\title{
Itinerário formativo em Clínica Ampliada: narrativas de uma cirurgiã-dentista
}

\author{
Graciela Soares Fonsêca*; Carlos Botazzo**; Fabiana Schneider Pires***; Simone Rennó Junqueira**** \\ * Doutora, Docente da Universidade Federal da Fronteira Sul \\ (UFFS), campus Chapecó \\ ** Doutor, Docente da Faculdade de Saúde Pública da \\ Universidade de São Paulo (FSP-USP) \\ *** Doutora, Docente da Faculdade de Odontologia da \\ Universidade Federal do Rio Grande do Sul (FO-UFRGS) \\ **** Doutora, Docente da Faculdade de Odontologia da \\ Universidade de São Paulo (FOUSP)
}

Recebido em 31/08/2017. Aprovado em 22/10/2017.

\begin{abstract}
RESUMO
A despeito das inovações propostas nos últimos anos ao modelo de formação em Odontologia, ele vem se mantendo centrado na aquisição de competências relacionadas ao desenvolvimento de procedimentos técnicos. O trabalho em saúde, contrariamente, demanda uma atuação ampliada e abrangente que corresponda às necessidades de um corpo vivo, subjetivado e complexo. $\mathrm{O}$ texto objetiva, a partir das narrativas de um itinerário formativo (que ocorreu pela experiência de uma cirurgiã-dentista no exercício da Clínica Ampliada) revelar elementos que contribuam com a discussão e auxiliem na busca de alternativas e enfrentamento no que se refere às incoerências entre o modelo de formação em Odontologia e o perfil profissional demandado pelo trabalho em saúde. A narrativa do itinerário formativo em clínica ampliada, inicialmente no âmbito de um projeto de pesquisa e, em seguida, no mundo do trabalho, aponta obstáculos e empecilhos relacionados ao desenvolvimento da Clínica Ampliada de saúde bucal, além de revelar benefícios e facilidades na incorporação de práticas de saúde que colocam o sujeito no centro. A narrativa demonstra, ainda, o potencial formativo da experiência em Clínica Ampliada. Evidencia-se a necessidade de desenvolver estudos e sistematizar experiências relacionadas à Clínica Ampliada de saúde bucal, no âmbito da formação e do trabalho, no sentido de fortalecer seu desenvolvimento.
\end{abstract}

Descritores: Saúde Bucal. Odontologia. Saúde Pública. Narração.

\section{INTRODUÇÃO}

A formação em Odontologia, a despeito das inovações propostas ao longo dos anos, vem mantendo sua conformação centrada na aquisição de competências relacionadas ao desenvolvimento de procedimentos técnicos voltados para o tratamento de dentes diagnosticados com algum tipo de doença ${ }^{1}$.

Sob a influência dos relatórios Flexner ${ }^{2}$ e $\mathrm{Gies}^{3}$, as Instituições de Ensino Superior (IES) 
adotaram um modelo de formação caracterizado por uma ciência das doenças e uma clínica experimental de restauração da suposta normalidade dos órgãos ${ }^{4,5}$, com pouco estímulo para o desenvolvimento de um olhar ampliado sobre o processo saúde-doença e uma atuação coerente com a complexidade que esse conceito coloca, realidade da maioria das escolas de Odontologia do Brasil e de outras partes do mundo $^{6-10}$

Já o trabalho em saúde é compreendido pela produção do cuidado à "corpos vivos" que se apresentam sob processos de subjetivação e mostram interação com o "socius" e o ambiente. O corpo vivo carrega marcas de uma história de vida com dilemas, sofrimentos, alegrias, satisfações, necessidades e culturas e não pode ser visto pelo olhar do corpo morto, fragmentado em órgãos, marcados por sinais e sintomas biológicos como, predominantemente, as IES ensinam ${ }^{4}$.

Assim, como frisa Merhy ${ }^{11}$, é necessário ir além do agir sobre o corpo biológico e compreender a complexidade do encontro micropolítico entre trabalhador e usuário.

Trata-se, portanto, de viabilizar uma clínica que coloque o sujeito (vivo) no centro das práticas, ampliando-a em seus aspectos teóricos e práticos ${ }^{12}$. Na perspectiva de reorganizar os serviços, faz-se necessário reorganizar as práticas, assumindo a integralidade como eixo da Clínica Ampliada. Esta impõe um compromisso com o sujeito doente - com a sua doença - no sentido de enxergá-lo de modo singular e assumir a responsabilidade pelo seu cuidado na busca de respostas para suas necessidades, equilibrando o combate às doenças com a produção de vida ${ }^{13}$. Além disso, a Clínica Ampliada demanda trabalho em equipe, escuta qualificada, atenção às singularidades, ponderação e partilha de dúvidas e incertezas com outros profissionais ou setores $^{12}$.
O corpo vivo produz vida à medida que interage no meio com outros corpos, $e$ esta vida é qualificada por uma existência que, inclusive, produz também doenças. Portanto, a clínica não pode prescindir de dar escuta a tais existências, que são produzidas em condições históricas por sujeitos que também se produzem, historicamente, em contextos e situações concretas. A ampliação da clínica nesta direção é, necessariamente, um exercício inter $e$ transdisciplinar, exigindo diálogo entre diversos saberes científicos $[\ldots]^{14}$.

As colocações postas até aqui revelam um questionamento: como os cirurgiões-dentistas podem atuar na lógica da Clínica Ampliada se ainda são formados sob os ditames da clínica reduzida e fragmentada?

O que se pretende nesse texto é, a partir das narrativas de um itinerário formativo - que ocorreu pela experiência de uma cirurgiã-dentista no exercício da Clínica Ampliada - revelar elementos que contribuam com essa discussão e auxiliem na busca de alternativas e enfrentamento desse paradoxo.

Os itinerários formativos descrevem os caminhos e as questões que afetam os saberes e práticas dos aprendizes durante o percurso formativo, desvelando áreas de transformação, crises e mudanças de paradigmas ${ }^{15}$. Ao narrar seu itinerário, o sujeito ressignifica $\mathrm{o}$ vivido oferecendo novos significados às experiências ${ }^{16}$ e construindo conhecimentos por meio delas ${ }^{17,18}$.

Quando nos deparamos com a chamada da Revista da ABENO para o número temático "Clínica Ampliada", valorizamos a intencionalidade do periódico em divulgar estudos e trabalhos sobre um tema ainda discutido de maneira incipiente no "mundo odontológico" e nos questionamos sobre a oportunidade de expormos uma experiência 
conjunta, vivida singularmente.

A partir daqui, pedimos licença ao leitor para redigir o texto utilizando a primeira pessoa do singular, em virtude dele estar baseado nas narrativas sobre o itinerário formativo de um dos autores.

\section{REVISITANDO O ITINERÁRIO FORMA-} TIVO COM A CLÍNICA AMPLIADA

Lembrei-me do meu itinerário formativo, desde os primórdios da graduação em Odontologia, e do quanto me faltou de aprendizagem e construção de competências relacionadas à Clínica Ampliada. Retificando, hoje eu tenho consciência que me faltou muito de aprendizagem em clínica de maneira geral. $\mathrm{Na}$ verdade, represento apenas um produto da conformação do ensino odontológico fragmentado e desvinculado da realidade ${ }^{1,19,20}$, como a maioria dos cirurgiões-dentistas.

Quando iniciei o doutorado, meu objeto de estudo era a formação em Odontologia e fui indicada à integrar a equipe de um projeto de pesquisa que estava propondo a experienciação da Clínica Ampliada de saúde bucal, uma maneira inovadora de "praticar" a Odontologia que, agora, deixaria de focar-se em "dentes" para abordar o sujeito inserido em um serviço de Atenção Primária à Saúde (APS)* .

A princípio, não conseguia compreender a proposta de maneira muito clara. O desafio foi se tornando maior à medida que eu tentava me aproximar dos temas centrais do projeto $\mathrm{e}$ conversava com os demais colegas que integravam a equipe. A cada encontro e a cada leitura, eu tinha uma sensação ótima de estar desvelando um mundo desconhecido, ao qual eu não havia sido apresentada em nenhum momento do meu itinerário formativo e que fazia muito sentido para mim. Mas, a sensação de que a proposta carregava um pouco de utopia e as incertezas sobre operacionalização delas cresciam proporcionalmente à construção de conhecimentos, o que é bem paradoxal.

Após alguns meses de preparo e organização do campo, iniciamos as atividades. A primeira etapa consistia em observar o atendimento das clínicas desenvolvidas por outros profissionais do centro de saúde que foi cenário do estudo. Nesse momento, nos deparamos com algumas dificuldades sendo a principal delas a resistência dos profissionais em abrir a intimidade de seus consultórios, resguardados e protegidos, para profissionais estranhos que "entendem de boca" e não teriam razão para querer conhecer abordagens voltadas para outras partes do corpo. Vencida essa barreira, acompanhamos a rotina de médicos, enfermeiros, técnicos de enfermagem, assistente social e nutricionista por um período de quatro meses. Nesse período, fui acometida por uma avalanche de reflexões, questionamentos, dúvidas, ânsia por conhecer mais sobre a abordagem clínica e sobre a interface entre a Odontologia e as demais profissões da área da saúde.

Um dos principais achados que surgiram após a observação de diferentes clínicas foi a dicotomia entre corpo e boca, extensamente discutida na Odontologia que se mostrou reforçada pelas práticas médicas, corroborando com Botazzo ${ }^{1}$. As práticas estão direcionadas para a boca (sem corpo), no primeiro caso, e para o corpo (sem boca), no segundo caso, configurando o que denominamos de clínica do corpo sem boca ${ }^{21}$.

\footnotetext{
*Projeto de pesquisa multicêntrico, intitulado Inovação na produção do cuidado em saúde bucal - possibilidades de uma nova abordagem na clínica odontológica para o Sistema Único de Saúde, desenvolvido com auxílio do Conselho Nacional de Desenvolvimento Científico e Tecnológico (CNPq) (Projeto 403153/2012-3) e da Fundação de Amparo à Pesquisa do Estado de São Paulo (FAPESP) (2013/11668-2), sob a coordenação do Professor Doutor Carlos Botazzo.
} 
Na sequência, iniciamos a clínica de saúde bucal. Eu, duas colegas cirurgiãs-dentistas e alguns estagiários de um curso de Odontologia, ao longo de dois anos, acolhemos as queixas, elaboramos projetos terapêuticos de maneira compartilhada com os usuários e realizamos procedimentos, encaminhamentos e discussões com outros profissionais sobre os casos, no intento de organizar a Clínica Ampliada de saúde bucal $^{22}$.

Cada caso era visto de maneira singular e demandava uma abordagem específica, exigindo de nós, como corresponsáveis no processo de cuidado, uma postura crítica, reflexiva e criativa no sentido de oferecer a melhor resposta para as necessidades apresentadas pelos usuários de modo coerente aos desejos expressos por eles. A prioridade era a oferta de uma alternativa para a queixa apresentada pelos usuários, na direção da resolubilidade, compreendida como a capacidade de satisfazer o conjunto de problemas de saúde identificados ${ }^{23}$.

Em alguns casos, a resposta mais adequada não estava ao nosso alcance por motivos variados, como a falta de apoio da rede ou a insuficiência dos recursos materiais disponíveis. No entanto, aos poucos, fui aprendendo que o importante era oferecer uma resposta, ainda que ela não fosse a ideal, conforme descrito no diário de pesquisa, redigido à época de desenvolvimento da experiência.

Apesar da nossa angústia por saber que o caso dela não teve a solução definitiva, ela saiu feliz porque tá segura que poderá viajar e reencontrar a família com o "seu dente" no lugar. Para nós, o caso não foi resolvido mas, para ela, houve atenção ao caso e a solução possível foi dada. Ela não queria viajar sem o dente, não importa se o problema foi totalmente resolvido ou não (Diário de pesquisa em 20 de março de 2013).
Ainda no que diz respeito à resolubilidade, percebi que a APS, no âmbito da saúde bucal, pode ser mais resolutiva do que a Política Nacional de Saúde Bucal (PNSB) propõe. É possível desenvolver um cuidado mais abrangente e incluir procedimentos que podem desafogar as filas para a especialidade e ampliar a capacidade resolutiva desse nível de atenção.

No entanto, o percurso de "desapego" das práticas odontocentradas foi complexo, sinalizando, no meu itinerário formativo, rupturas, crises, incompreensão e medo, dentre outros sentimentos ${ }^{15}$. As principais dificuldades estiveram ligadas ao "como fazer" a Clínica Ampliada. Eu conhecia os passos para execução dos procedimentos usualmente realizados na APS mas, isso representa apenas uma fração do que eu deveria oferecer aos meus pacientes. A seguir, insiro fragmentos do meu diário que revelam algumas dessas dificuldades:

Na verdade, a insegurança é um sentimento bem comum no nosso grupo. Na semana anterior, por exemplo, eu e as colegas do projeto, estávamos conversando sobre como conduzir uma consulta individual pautada na bucalidade, ampliando a escuta. Não sabemos!...risos! Fomos pedir ajuda do mestre e ele nos respondeu que basta se interessar pela vida do paciente e interrelacionar as condições de vida com a saúde. Parece fácil? Pois não é. (Diário de pesquisa em 06 de março de 2014).

Até o momento, ainda temos muitas dúvidas com relação a como realizar um exame clínico abrangente e a interpretar achados extrabucais. Atribuímos isso a nossa formação que foi centrada nas características e técnicas bucais ou, pior, características e técnicas dentárias (Diário de pesquisa em 17 de maio de 2014).

Mesmo que o processo tenha sido marcado por esses sentimentos conflituosos, cada vez que 
os usuários atendidos manifestavam sua satisfação, eu acreditava ainda mais nesse "novo fazer em saúde bucal" e me sentia motivada a buscar mais conhecimentos para subsidiar as ações. No meu diário de pesquisa, aparecem alguns relatos relacionados à isso:

O senhor João [nome fictício] se manifestou dizendo que estava satisfeito com a abordagem feita e que era isso que ele esperava de um serviço de saúde (Diário de pesquisa em 15 de maio de 2014).

Bom, voltando a resposta para pergunta que eu me fiz: O que seria esse 'tudo que eu fiz por elas' (falas de duas usuárias)? Cheguei a conclusão que eu não fiz muito mas, o que elas julgaram como 'tudo', na verdade, se refere ao fato de tê-las ouvido, me interessado pela história delas, conversado sobre os problemas bucais ou não e, acima de tudo, ter buscado em parceria com elas, uma solução para o caso. Incrível mas a conclusão é: a maior inovação encontra-se na escuta atenta e no consequente significado que um cuidado partilhado com o paciente, maior interessado nessas ações, adquire e se torna resolutivo (Diário de pesquisa em 02 de outubro de 2014).

A intensificação do uso de tecnologias leves no cuidado na APS foi revelando, no decorrer da experiência, benefícios que me faziam acreditar cada vez mais na Clínica Ampliada como modelo de atuação clínica mais responsivo aos anseios dos usuários. No encontro com o usuário, era realizado o acolhimento momento em que o outro mostra sua presença por meio de falas e afetos e é ouvido pelo profissional, um "agir centrado nas tecnologias leve-relacionais". O acolhimento apresenta um efeito fundamental na elaboração do projeto terapêutico compartilhado porque reconhece o outro como "legítimo, desejante e sabido" e enxerga suas necessidades como o centro do processo, proporcionando uma produção do cuidado mais competente e baseada "nos modos de produção das distintas formas de viver", essencial no campo da saúde, na qual "o organizador de sentido dos seus agires é sempre a lógica da vida do usuário, o mundo das suas necessidades, que se fazem aí presentes no ato do encontro" $" 11$.

Consideramos como centralmente terapêutico os processos de produção do cuidado medidos pela capacidade de manter ou enriquecer as redes de conexões existenciais de alguém, e não simplesmente fazer os processos de remissões de sintomas ou sinais, por ideais de curas como simples recuperações de funções orgânicas ${ }^{11}$.

Com vistas a escutar, entender e acolher as queixas que motivaram os usuários a procurarem o serviço, o projeto previa o uso de dispositivos como consultas individuais - realizadas em consultórios médicos e/ou de enfermagem - e anamneses coletivas - atividades realizadas em grupos de usuários com a intenção de escutar, acolher, promover vínculo e permitir que eles falassem sobre seu mal-estar, sua condição clínica, seus sintomas, suas expectativas, sua vida. $\mathrm{O}$ trecho que segue agrega na compreensão dessa temática:

[...]Experimentamos algumas anamneses coletivas e individuais - realizadas nos consultórios médicos - ampliamos a escuta dos nossos pacientes, tentamos organizar o plano terapêutico de acordo com os significados atribuídos pelos pacientes $e$ estamos desenvolvendo um processo de trabalho partilhado com profissionais técnicos e auxiliares (na verdade, são estudantes estagiárias da escola técnica). Até o momento posso afirmar que o projeto, de fato, está inovando. Em toda minha experiência clínica, não havia vivenciado 
nada próximo do que estamos desenvolvendo. Ao ampliar a escuta, fora do consultório odontológico, o paciente se "desodontologiza", ou seja, abandona a ideia de que os dentes são os elementos centrais da prática em saúde bucal. O paciente consegue expressar seus modos de vida, seus anseios, angústias, desejos $e$ articula-se tudo isso com a condição bucal trazendo à cena os aspectos da bucalidade (Diário de pesquisa em 06 de março de 2014).

Assim, como afirma Souza ${ }^{14}$, para nossas práticas no cenário de estudo, a bucalidade foi utilizada como um "conceito-ferramenta", colocando em "xeque a restrição da clínica odontológica, convocando-a para a necessidade de uma clínica de saúde bucal e mais que isto: de rejuntar saberes desta Clínica Ampliada com os da saúde bucal coletiva". A ideia de bucalidade encontra sua conceituação nas publicações de Botazzo $^{1,24-27}$ que compreende a cavidade bucal como um território dotado de capacidade para desenvolver "trabalhos" - os trabalhos bucais, distribuídos em três vertentes: a manducação, o erotismo e a linguagem, que expressam três dimensões da vida do homem em sociedade e, por isso, podem ser entendidos como a "produção social da boca humana".

O conceito de bucalidade traz para a cena a não restrição da saúde (bucal) à forma clínica e a insuficiência da teoria odontológica para recuperar o homem por inteiro, frisando a influência dos determinantes sociais no adoecimento bucal ${ }^{24}$. A boca sofre desgaste pelos modos de viver e trabalhar e não é a-histórica ou indeterminada. $\mathrm{O}$ uso do corpo biológico difere de acordo com as classes sociais e a inserção dessas classes no processo produtivo. $\mathrm{O}$ padrão de desgaste físico-biológico encontra-se diretamente vinculado ao uso social do corpo, ou seja, esse padrão é socialmente determinado pelos modos de produção ${ }^{1}$.

A Clínica Ampliada em saúde bucal necessita de, pelo menos, dois movimentos, simultâneos e interligados: um, interno, em direção à boca como órgão-parte do corpo e ao próprio corpo clínico anatomopatológico; este movimento exige incorporação de saberes específicos do adoecer bucal, mas que se comuniquem com os demais saberes que a clínica médica produziu sobre o funcionamento do corpo. [...] o que se pretende em nossa proposta de ampliação é romper com a fragmentação no conhecimento e nas intervenções sobre o corpo. $O$ segundo movimento, que não é peculiar apenas à clínica odontológica, é o de ampliar a noção de corpo biológico para além do arranjo funcional de órgãos, células e moléculas, no qual se manifestam doenças. Nesse sentido, o biológico adquire a conotação do "vivo" e de sua interação sistêmical.

\section{O ITINERÁRIO FORMATIVO NO MUNDO DO TRABALHO}

Ao concluir o doutorado, comecei a trabalhar em uma Unidade Básica de Saúde (UBS). Em conjunto com uma técnica e uma auxiliar de saúde bucal, conformávamos a equipe de saúde bucal vinculada às quatro equipes de Estratégia Saúde da Família (ESF), responsáveis por uma área que comportava em média 15.000 pessoas. Nos primeiros dias, o sentimento era de medo e insegurança, uma vez que eu tinha convicção de que seria difícil me adequar ao processo de trabalho que seria desenvolvido ali após vivenciar a Clínica Ampliada de saúde bucal e saber que ela, além de possível, gerava resultados positivos no que diz respeito à resolubilidade, à corresponsabilização do cuidado, à satisfação dos usuários e a sensação de 
que as intervenções eram úteis e faziam diferença na vida das pessoas.

Uma análise inicial daquela realidade revelou empecilhos para o exercício da Clínica Ampliada. A área de abrangência era extensa, com uma enorme demanda reprimida e sem possibilidade de organização por vulnerabilidade. Além disso, o consultório encontrava-se organizado em um pequeno espaço físico, com apenas uma cadeira odontológica, e não havia outras salas ou consultórios médicos e/ou de enfermagem disponíveis para realização das consultas individuais ou anamneses coletivas. A gestão era realizada por uma Organização Social (OS) que exigia o cumprimento de metas baseadas em número de procedimentos realizados e pacientes atendidos.

Tal como apresentado por Pires e Botazzo $^{28}$, a organização tecnológica para o cuidado em saúde bucal, proposta pela Clínica Ampliada como vivenciada por mim em uma UBS tradicional, não encontrava espaço no modelo de atenção em saúde bucal vigente.

Os questionamentos e solicitações que eu comecei a fazer geraram, a princípio, estranhamento e até enfretamento por parte de alguns colegas. Um exemplo foi a resistência da Auxiliar de Saúde Bucal com relação ao uso de tecnologias leves de cuidado na rotina do consultório odontológico. Por conta da incompreensão, ela chegou à sugerir para a gestão que havia problemas no processo de trabalho que eu estava tentando desenvolver. Outra reclamação surgiu quando eu solicitei a ela que não orientasse os usuários que chegassem queixando-se de dor à retornarem no dia seguinte quando o número limite de atendimento de urgência estabelecido (dois pacientes por turno) já tivesse extrapolado. Eu fazia questão de escutar todos eles e oferecer uma reposta, mesmo que temporária, para o problema e orientar um retorno de maneira adequada.

Os demais membros da equipe, no início, também estranharam as minhas tentativas de discutir casos ou solicitar esclarecimentos relacionados aos pacientes. No entanto, com o passar dos dias, eles começaram a me procurar e, aos poucos, conseguimos nos aproximar de uma atuação em equipe multiprofissional, coerente com a complexidade dos casos que eram atendidos no serviço.

Em muitos momentos, as incoerências e a falta de resolubilidade da clínica odontocentrada apareciam por meio de casos não resolvidos e usuários que insistiam em procurar a unidade, uma vez que esse era o único recurso disponível. Lembro-me com riqueza de detalhes do caso de uma criança de seis anos sobre o qual tomei conhecimento quando a mãe bateu na porta do consultório dizendo que precisava de ajuda. Ao iniciar a narrativa da sua saga, entrou em pranto e afirmou que a menina perdia "pedaços de dentes" desde que eles irrompiam na cavidade bucal, ainda que ela se preocupasse com a alimentação e a higiene bucal. O motivo do choro residia na culpabilização dela por outros profissionais - incluindo cirurgiões-dentistas, médicos e enfermeiros - que afirmava tratar-se de um caso de "cárie de mamadeira" e atribuíam as causas do problema à falta de cuidados com a criança. A princípio, eu não conseguia compreender o que se passava com a menina mas, após uma longa conversa com a mãe, com outros profissionais da equipe que acompanhavam a família e depois da análise do prontuário, conclui que se tratava de um caso relacionado à má formação do esmalte dentário por conta de uma sífilis congênita. Quando eu e a médica conversamos com a mãe e explicamos o que estava acontecendo, ela deu um suspiro de alívio. Pactuamos, então, um projeto terapêutico e, por conta do vínculo de confiança estabelecido, conseguimos oferecer respostas 
satisfatórias com os recursos que a UBS profissional.

dispunha.

Voltando às dificuldades para o desenvolvimento da Clínica Ampliada, merece destaque a falta de apoio da rede de atenção à saúde do município para os casos complexos que não se encaixavam nos protocolos de encaminhamento para a especialidade mas, demandavam soluções de outros níveis de atenção. Em alguns casos, foi necessário solicitar encaminhamentos de maneira informal por meio de ligações para às interlocuções de saúde bucal da região.

No entanto, mesmo com as limitações postas, o sujeito com suas queixas continuava ocupando o centro das minhas práticas e isso fazia diferença no desenvolvimento do trabalho.

Vale ressaltar que algumas facilidades foram encontradas nesse percurso, como a autorização da gestora da unidade para utilização do prontuário único da família, sem a necessidade de preencher o odontograma. A gerente me instruiu a experimentar o método SOAP (método de registro em que se verificam os aspectos subjetivos e objetivos, a avaliação do profissional e plano terapêutico), utilizado pelos demais profissionais, e assim eu conduzia as anotações. Os registros nos prontuários facilitaram a comunicação com os colegas e intensificaram o desenvolvimento do trabalho de maneira interprofissional.

A experiência durou apenas três meses, mas foi possível perceber que é possível ampliar a clínica de saúde bucal nos espaços de produção do cuidado em saúde, ainda que existam empecilhos de natureza diversa. Além disso, ao ser sensibilizado para a construção de competências voltadas para essa abordagem, dificilmente um profissional conseguirá retornar ao modelo de clínica reduzido e fragmentado com o qual teve contato durante a formação e, possivelmente, reproduziu durante a experiência

\section{O PROCESSO FORMATIVO INDUZIDO PELA CLÍNICA AMPLIADA \\ O potencial pedagógico da experiência em} Clínica Ampliada aparece em distintos momentos da escrita do diário, tanto relacionada aos estudantes de graduação como ao itinerário formativo da cirurgiã-dentista. Os fragmentos abaixo ajudam a compreender essa potencialidade:

[...] oportunidade de poder refletir sobre nosso trabalho, abandonando o trabalho acrítico comumente realizado para um trabalho que tem significado para nós e, sobretudo, para o paciente. Deixamos de curar para cuidar daqueles que nos procuram com tantos problemas e que desejam atenção às suas queixas e empenho para solucioná-las (Diário de pesquisa em 02 de outubro de 2014).

Gostaria de acrescentar à essa reflexão sobre meu próprio processo de aprendizagem que, coerente com o que eu venho estudando e pesquisando sobre a formação em saúde a nível de graduação, estou cada vez mais convicta de que o contato com a realidade e tudo o que vem junto com ela desperta reflexões que eu nunca encontrei em livros ou artigos. $O$ conhecimento que venho construindo é muito particular (com certeza muito diferente do que as minhas colegas vêm aprendendo) porque é estritamente enviesado pela minha forma de enxergar esse mundo do trabalho e, essa forma de ver está diretamente ligada à minha história, ao que é importante pra mim e ao meu conhecimento prévio construído com base nas inúmeras experiências que eu acumulei nesses anos. Posso afirmar, sem medo de errar, que esse um ano de imersão $e$ 
trabalho na unidade de saúde me transformou e mudou - e ainda muda conceitos, crenças, postura, etc. Estou construindo um conhecimento sólido, dotado de muitos significados, crescente a cada nova experiência, a cada nova reflexão. Acredito que isso, por isso só, é suficiente para nos motivar a continuar buscando formas de inserção dos alunos de graduação no SUS, por mais obstáculos e empecilhos que identificarmos nesse percurso (Diário de pesquisa em 09 de outubro de 2014).

Os cenários de produção de saúde são dotados de potencial educativo uma vez que se constituem em espaços de problematização, diálogo e reflexão sobre as práticas ${ }^{29,30}$. Assim, as relações que se estabelecem no cotidiano das práticas contribuem para a construção de aprendizagem significativa ${ }^{29,31}$.

Paralelamente e, de modo atrelado à toda essa vivência, eu desenvolvia meu projeto de doutorado que objetivava elaborar um modelo de estágio curricular supervisionado, que envolvesse a experienciação da clínica, para um determinado curso de Odontologia. Por conta disso, meu olhar também esteve voltado para o potencial pedagógico proporcionado por essa experiência aos estagiários e eu pude, inclusive, ouvir comparações entre o que se aprendia no exercício da Clínica Ampliada e o que era ensinado por meio do modelo de ensino clínico da IES. Estudantes que não participaram do estágio, preceptores e gestores também foram ouvidos, por meio de grupos focais ou entrevistas individuais ${ }^{20}$.

Após analisar e triangular os dados levantados, concluímos que o ensino de Odontologia, como moldado nas escolas contemporâneas, encontra-se despido de realidade, voltando suas práticas para elementos dentários visto de modo fragmentado e isolado, diminuindo a complexidade do adoecimento bucal e, em consequência, reduzindo a clínica à reprodução de procedimentos e técnicas. Foi a partir dessas constatações que elaboramos o conceito de ensino da Odontologia 'in vitro' e apontamos alguns caminhos para iniciar um período de superação desse paradigma ${ }^{20}$.

\section{CONSIDERAÇÕES FINAIS}

A narrativa reflexiva do itinerário formativo em Clínica Ampliada, indo da experiência no projeto de pesquisa à inserção no mundo do trabalho, aponta os principais obstáculos e empecilhos relacionados ao desenvolvimento da Clínica Ampliada de saúde bucal, além de revelar benefícios e facilidades na incorporação de práticas de saúde que colocam o sujeito no centro.

Além disso, o percurso narrado demonstra o potencial da experiência em Clínica Ampliada para a formação, sugerindo a presença do método dialético de ensino em que a aprendizagem se dá pela problematização e reflexão sobre a prática.

Sugerimos a experienciação de abordagens ampliadas no cuidado em saúde bucal, na formação e nas práticas, no sentido de propiciar maior resolubilidade e satisfação dos usuários.

É imperativo o desenvolvimento de estudos e a sistematização de experiências relacionadas à Clínica Ampliada de saúde bucal no intuito de fortalecê-la e gerar maiores subsídios para sua incorporação no ensino e no trabalho.

\section{ABSTRACT \\ Training itinerary in Extended General Practice: narratives of a dentist}

In spite of the innovations proposed in the last years to the model of training in dentistry, it has been centered in the acquisition of competencies related to the development of technical procedures in a dentist-centered way. Contrary, work in health, demands a broad and 
comprehensive action that corresponds to the subjectivized and complex needs of a living body. Based on the narratives of a formative itinerary (which occurred through the experience of a dentist in the practice of the extended clinic). Our objective is to reveal elements that contribute to the discussion and assist in the search for alternatives and coping with the inconsistencies between the model of training in dentistry and the professional profile demanded by the work in health. Encouraged by the call of ABENO's Magazine, the authors saw the opportunity to report a joint experience, based on experiences lived singularly. The narrative of the formative itinerary in an expanded clinic, initially within the framework of a research project and then in the world of work, points out obstacles and obstacles related to the development of the expanded oral health clinic, besides revealing benefits and facilities in the incorporation of practices that put the subject at the center. The narrative also shows the formative potential of the extended clinical experience. There is evidence of the need to develop studies and systematize experiences related to the expanded oral health clinic, in the field of training and work, in order to strengthen its development.

Descriptors: Oral Health. Dentistry. Public Health. Narration.

\section{REFERÊNCIAS}

1. Botazzo C. Diálogos sobre a boca. São Paulo: Editora Hucitec; 2013.

2. Flexner A. Medical education in the United States and Canada. New York: Carnegie Foundation for the Advancement of Science, 1910. [Acesso em: 02 dez. 2015]. Disponível em: http://www.carnegiefoundation.org/files/ elibrary.

3. Gies WJ. Dental Education in the United States and Canada. New York: The Carnegie Foundation for the advancement of teaching, 1926.

4. Ceccim RB, Carvalho YM. Ensino da saúde na integralidade: a educação dos profissionais de saúde no SUS. In: Pinheiro R, Ceccim RB, Mattos RA. Ensinar saúde: a integralidade e o SUS nos cursos de graduação na área da saúde. Rio de Janeiro: CEPESC-IMS/UERJ/ABRASCO; 2011. p. 69-92.

5. Feuerwerker LMM. Micropolítica e saúde: produção do cuidado, gestão e formação. [tese de livre-docência]. São Paulo: Universidade de São Paulo, Faculdade de Saúde Pública; 2012.

6. Hendricson WD, Cohen PA. Oral health care in the $21^{\text {st }}$ Century: Implications for ental and medical education. Academic Medicine. 2001 Dec;76(12):1181-206.

7. Haden NK, Hendricson WD, Kassebaun DK, Ranney RR, Weinstein G, Anderson EL, et al. Curriculum Change in Dental Education, 2003-09. J Dent Educ. 2010; 74(5):539-57.

8. Kassenbaum DK, Hendricson WD, Taft T, Haden NK. The dental curriculum at north american dental institutions in 2002-03: A survey of current structure, recent innovations, and planned changes. J Dent Educ. 2004;68(9):914-31.

9. Bertolami CN. Rationalizing the dental curriculum in light of current disease prevalence and patient demand for treatment: Form vs. Content. J Dent Educ. 2001; 65(8):725-35.

10. Alonso MS, Antoniazzi JH. Livro do projeto latino-americano de convergência em educação odontológica (PLACEO). São Paulo: Artes Médicas; 2010.

11. Merhy EE. Ver a si o ato de cuidar. In: Capozzolo AA, Casseto SJ, Henz AO, organizadores. Clínica comum: itine-rários de uma formação em saúde. São Paulo: Hucitec; 2013. p.248-267.

12. Campos, GWS. Saúde Paidéia. São Paulo: Editora Hucitec; 2003.

13. Brasil. Ministério da Saúde. Secretaria de Atenção à Saúde. Departamento de Atenção Básica. Coordenação Nacional de Saúde Bucal. Diretrizes da Política Nacional de Saúde Bucal. Brasília: Ministério da Saúde, 200b. [Acesso em: 25 jun. 2015]. Disponível em:http://bvsms.saude.gov.br/bvs/publicacoes/ politica_nacional_brasil_sorridente.pdf. 
14. Souza ECF. Bucalidade: conceitoferramenta de religação entre clínica e saúde bucal coletiva. Ciênc Saúde Colet. 2006 Mar; 1(1):24-8.

15. Silveira R, Pinheiro R. O mundo como fronteira: itinerários formativos de estudantes de medicina nas experiências de internato Rural na Amazônia. In: Gerhardt TE, Pinheiro R, Ruiz ENF, Silva Junior AG. Itinerários terapêuticos: integralidade no cuidado, avaliação e formação em saúde. Rio de Janeiro: CEPESC editora, IMS/ UERJ, ABRASCO, 2016.

16. Bondía JL. Notas sobre a experiência e o saber da experiência. Rev Bras Educ. 2002;19:20-8.

17. Kolb D. Experiential learning-experience as the source of learning and development. New Jersey: Prentice-Hall;1984.

18. Schön DA. La formación de profesionales reflexivos. Hacia un nuevo diseño de la enseñanza y aprendizaje en las profesiones. Barcelona: Ediciones Paidós; 1992.

19. Araujo ME. Palavras e silêncios na educação superior em odontologia. Ciênc Saúde Colet. 2006;11(1):179-82.

20. Fonsêca GS. Formação pela experiência: Revelando novas faces e rompendo os disfarces da odontologia 'in vitro'. Tese apresentada à Faculdade de Odontologia da Universidade de São Paulo para obtenção do título de Doutor em Ciências Odontológicas.

21. Fonsêca GS, Junqueira SR, Botazzo C, Carvalho YM, Araujo ME. A clínica do corpo sem boca. Saúde Soc. 2016 Dec; 25(4): 1039-49.

22. Botazzo C, Fonsêca GS, Pires FS, Souza CR, Junqueira SR, Pezzato LM. et al. Inovação na produção do cuidado em saúde bucal. Possibilidades de uma nova abordagem na clínica odontológica para o Sistema Único de Saúde. Relatório Técnico. São Paulo; 2015.

23. Merhy EE. O ato de governar as tensões constitutivas do agir em saúde como desafio permanente de algumas estratégias gerenciais. Ciênc Saúde Colet. 1999. 4(2): 305-15.
24. Botazzo C. Da arte dentária. São Paulo: Hucitec/Fapesp, 2000.

25. Botazzo C. Sobre a bucalidade: notas para a pesquisa e contribuição ao debate. Ciênc Saúde Colet. 2006 Jan/Mar;11(1):7-17.

26. Botazzo C. A bucalidade no contexto da estratégia saúde da família: ajudando a promover saúde para indivíduos, grupos e famílias. In: Moysés ST, Kriger L, Moysés SJ, editores. Saúde Bucal das Famílias: Trabalhando com evidências. São Paulo: Artes Médicas; 2008a, p.81-8.

27. Botazzo C. Pensando a integralidade da atenção e a produção do cuidado em saúde bucal. Perspectivas teóricas e possibilidades práticas para a clínica odontológica à luz do conceito de bucalidade. In: Macau M, editora. Saúde bucal coletiva. Implementando ideias, concebendo integralidade. Rio de Janeiro: Rubio; 2008b, p.3-15.

28. Pires FS, Botazzo C. Organização tecnológica do trabalho em saúde bucal no SUS: uma arqueologia da política nacional de saúde bucal. Saúde Soc. 2015. 24(1): 27384.

29. Ceccim RB. Educação permanente em saúde: desafio ambicioso e necessário. Interface - Comunic Saúde Educ. 2005 Fev;9(16):161-77.

30. Ceccim RB, Feuerwerker LCM. O quadrilátero da formação para a área da saúde: ensino, gestão, atenção e controle social. Physis. 2004;14(1):41-65.

31. Faria RMB. Institucionalização da política de educação permanente para o Sistema Único de Saúde: Brasil, 1997-2006. 2008. Tese (Doutorado) - Faculdade de Medicina, Universidade de São Paulo, São Paulo. 2008.

Correspondência para

Graciela Soares Fonsêca e-mail: graciela.fonseca@uffs.edu.br Rodovia BR 158 - Km 405

Bloco dos professores, sala 317 85301-970 Chapecó, SC 